\title{
Karyotype structure and NOR activity in Brazilian Smilax Linnaeus, I 753 species (Smilacaceae)
}

\author{
Daniel Pizzaia', Vanessa M. Oliveira-Maekawa², Aline R. Martins ${ }^{3}$, \\ Mateus Mondin', Margarida L.R. Aguiar-Perecin' \\ I Department of Genetics, Luiz de Queiroz College of Agriculture, ESALQ, University of São Paulo, Avenida \\ Pádua Dias, 11, 13418-900 Piracicaba, SP, Brazil 2 Department of Plant Biology, The University of Cam- \\ pinas, UNICAMP, Barão Geraldo, 13083-970, Campinas, SP, Brazil 3 Department of Biological Sciences, \\ Luiz de Queiroz College of Agriculture, ESALQ, University of São Paulo, Avenida Pádua Dias, 11 13418-900, \\ Piracicaba, SP, Brazil
}

Corresponding author: Margarida L. R. Aguiar-Perecin (mlrapere@usp.br)

Academic editor: Puneet Kumar | Received 13 May 2019 | Accepted 5 July 2019 | Published 22 August 2019

http://zoobank.org/E41B30A6-8807-4166-B535-AD8EDF587EB6

Citation: Pizzaia D, Oliveira-Maekawa VM, Martins AR, Mondin M, Aguiar-Perecin MLR (2019) Karyotype structure and NOR activity in Brazilian Smilax Linnaeus, 1753 species (Smilacaceae). Comparative Cytogenetics 13(3): $245-263$. https://doi.org/10.3897/CompCytogen.v13i3.35775

\begin{abstract}
The genus Smilax Linnaeus, 1753 (Smilacaceae) is a large genus of dioecious plants distributed in tropical, subtropical and temperate regions. Some Smilax species have medicinal importance and their identification is important for the control of raw material used in the manufacture of phytotherapeutical products. The karyotypes of seven Brazilian Smilax species were investigated. Mitotic metaphases of roots from young plants were analysed in Feulgen-stained preparations. The karyotypes were asymmetric and modal with $2 \mathrm{n}=2 \mathrm{x}=32$ chromosomes gradually decreasing in size. In S. goyazana A De Candolle \& C De Candolle, 1878, a polyploid species, $2 \mathrm{n}=4 \mathrm{x}=64$. In all the species, the large and medium-sized chromosomes were subtelocentric and submetacentric and the small chromosomes were submetacentric or metacentric. Their karyotypes were quite similar, with differences in the arm ratio of some chromosomes. S. fuminensis Steudel, 1841 differed from the other species by having a large metacentric chromosome 1 . These findings suggest that evolution occurred without drastic changes in the chromosomal structure in the species analyzed. Terminal secondary constrictions were visualized on the short arm of some chromosomes, but they were detected only in one homologue of each pair. Due to the terminal location and the degree of chromosome condensation, secondary constrictions were not visualized in some species. The nucleolus organizer regions (NORs) were mapped by silver-staining and fluorescent in situ hybridization (FISH) in S. rufescens Grisebach, 1842 and S. fluminensis. Silver-staining and FISH signals were colocalized on the short arms of
\end{abstract}

Copyright Daniel Pizzaia et al. This is an open access article distributed under the terms of the Creative Commons Attribution License (CC BY 4.0), which permits unrestricted use, distribution, and reproduction in any medium, provided the original author and source are credited. 
six chromosomes in S. rufescens and four chromosomes in S. fluminensis. In FISH preparations, one of the largest chromosomes had the secondary constrictions highly decondensed in some cells. This finding and the heteromorphism observed in Feulgen-stained chromosomes suggest that differential rRNA gene expression between homologous rDNA loci can occur in some cells, resulting in different degrees of ribosomal chromatin decondensation. The presence of a heteromorphic chromosome pair in S. rufescens, S. polyantha Grisebach, 1842 and S. goyazana suggests a chromosomal sex determination in these dioecious species.

\section{Keywords}

Smilax, karyotype, chromosomal evolution, nucleolus organizer region (NOR), Silver-staining, FISH, $45 \mathrm{~S}$ rDNA

\section{Introduction}

The genus Smilax Linnaeus, 1753 (Smilacaceae) is a large genus of dioecious plants distributed in tropical, subtropical and temperate regions. The genus has approximately 300 species, and their classification has been controversial (see Mangaly 1968). This genus had been assigned to the family Liliaceae, but for the past 20 to 30 years, botanists have accepted Smilacaceae as a distinct family belonging to the order Liliales according to APG III (The Angiosperm Phylogeny Group 2009). The genus Smilax comprises the largest number of species within the Smilacaceae family, of which 32 species occur in Brazil (Andreata 1995, 2009).

Some Smilax species have medicinal importance. Roots have been used as antisyphilitic, anti-inflammatory and antimicrobial remedies or as antioxidant agents (Andreata 1995, de Souza et al. 2004, Cox et al. 2005). The unequivocal characterization of Smilax species with potential medicinal applications is highly important, but some problems in the taxonomic identification of some species have been reported. The genus has high variability in morphology, and morphological features were described for species in Brazil (Andreata 2009), North America (Mangaly 1968) and Asia (Koyama 1960, Fu et al. 1995). Leaf morphology has been emphasized as an important feature for species identification by Mangaly (1968) and Andreata (2009). The possible evolution of inflorescences in Smilax and Heterosmilax Kunth, 1850 was considered (Kong et al. 2007). Reports on the morphoanatomy of vegetative organs (Martins and Appezzato-da-Gloria 2006, Martins et al. 2010, 2012) and molecular phylogeny (Sun et al. 2015) have also contributed to species systematic.

The characterization of karyotypes in higher plants has evolutionary and taxonomic significance. Some studies on Smilax cytogenetics have reported chromosome numbers and karyotype characterization. Chromosome numbers of $\mathrm{n}=16$ were described for most species, but $\mathrm{n}=13$ and $\mathrm{n}=15$ were also recorded (Speese 1939, Mangaly 1968, Mehra and Sachdeva 1976, Vijayavalli and Mathew 1989, Fu and Hong 1990, Fu et al. 1993, 1995, Huang et al. 1997, Kong et al., 2007, Pizzaia et al. 2013; Sun et al. 2015). Some polyploids $(n=32,48$ and 64) have been found in Asian species (Vijayavalli and Mathew 1989, Fu and Hong 1990, Fu et al. 1993, 1995, Huang et al. 1997, Kong et al. 2007, Sun et al. 2015). The karyotypes of the species analyzed were asymmetric and modal, with most chromosomes being submetacentric and subtelo- 
centric and all of them gradually decreasing in size (Vijayavalli and Mathew 1989, Fu and Hong 1990, Fu et al. 1993, 1995, Kong et al. 2007, Pizzaia et al. 2013). Smilax species are dioecious and heteromorphic chromosomes have been detected in some species, and are thought to be sexual chromosomes (Mangaly 1968, Vijayavalli and Mathew 1989, Fu et al.1995, Pizzaia et al. 2013). Secondary constrictions and satellites were detected in few species (Vijayavalli and Mathew 1989, Fu et al. 1995 and Pizzaia et al. 2013).

Pizzaia et al. (2013) described for the first time the nucleolus organizer regions of a Smilax species (S. rufescens), which were mapped by silver staining (Ag-NOR) and fluorescent in situ hybridization (FISH) of $45 \mathrm{~S}$ rDNA probes. Silver signals colocalized with rDNA sites were observed on the short arms of six chromosomes.

In the present study, we investigated the karyotype characteristics of seven species of Brazilian species of Smilax using conventional techniques. We compared the positions of $45 \mathrm{~S}$ rDNA sites of $S$. rufescens with the sites in S. Aluminensis. Procedures to germinate wild-collected seeds to obtain plants providing roots for cytogenetic research were also developed. We aimed to analyze aspects of karyotype evolution in these species and to contribute to their taxonomic treatment.

\section{Material and methods}

Seeds from wild plants collected from southern, southeastern, northeastern and western central Brazil were used (Table 1). The plants are dioecious, vines or herbaceous vines, or rarely, subshrubs or shrubs such as S. goyazana and S. brasilienesis Sprengel, 1825 (Andreata 1995). The plants were identified by Dr. R.H.P Andreata (Santa Ursula University, Brazil) and were incorporated into the ESA herbarium (ESALQ, USP).

Experiments to germinate seeds to obtain plants were evaluated as reported by Pizzaia et al. (2013). Briefly, the seeds were germinated in plastic boxes containing Sphagnum moss, at $27^{\circ} \mathrm{C}$. The seedlings were transferred to plastic pots containing vegetable soil + vermiculite and maintained under screenhouse conditions with the temperature varying from $20^{\circ} \mathrm{C}$ to $32^{\circ} \mathrm{C}$. The sex of the young plants was not known.

Roots excised from young plants were pretreated with 8-hydroxyquinoline combined with cycloheximide, a protein synthesis inhibitor that induces chromosome condensation. Some treatments were evaluated, and in most cases, two treatments were used: combinations of $300 \mathrm{mg} / \mathrm{L}$ 8-hydroxyquinoline with $1.25 \mathrm{mg} / \mathrm{L}$ or $20 \mathrm{mg} / \mathrm{L}$ cycloheximide at $28^{\circ} \mathrm{C}$ for $3 \mathrm{~h}$ and $2.5 \mathrm{~h}$, respectively. The roots were then fixed in 3:1 ethanol:acetic acid and kept at $4{ }^{\circ} \mathrm{C}$. The roots were Feulgen-stained as previously described (Bertão and Aguiar-Perecin 2002). For karyotype analysis, chromosomes of at least five metaphase spreads were measured. Chromosomes were identified according to their absolute length $(\mu \mathrm{m})$, relative length (expressed as percentage of the haploid set), arm ratio (large arm/short arm) and chromosome types were designated according to Levan et al. (1964). The ratio of the largest chromosome/smallest chromosome was also described. The classification of the karyotypes according to their asymmetry (Stebbins, 1971) was adopted. The evaluation of the relative chromosome length in 
Table I. Origin of collection, chromosome number, chromosome and haploid set length $(\mu \mathrm{m})$ and ratio of the largest/smallest chromosomes of the Smilax species.

\begin{tabular}{lccccc}
\hline \multicolumn{1}{c}{ Species } & Origin $\dagger$ & 2n & \multicolumn{3}{c}{ Chromosome length } \\
\cline { 4 - 6 } & & & Range $(\boldsymbol{\mu m})$ & $\begin{array}{c}\text { Ratio (largest/ } \\
\text { smallest })\end{array}$ & $\begin{array}{c}\text { Haploid set } \\
(\boldsymbol{\mu m})\end{array}$ \\
\hline S. rufescens Grisebach, 1842 & Ilha do Cardoso (SP) & 32 & $5.62-1.84$ & 3.05 & 54.24 \\
S. fluminensis Steudel, 1841 & Uruana (GO) & 32 & $6.41-1.33$ & 4.82 & 43.47 \\
& Itirapina (SP) & 32 & $6.48-1.31$ & 4.95 & 43.32 \\
S. polyantha Grisebach, 1842 & Botucatu (SP) & 32 & $5.85-1.92$ & 3.05 & 44.09 \\
& Mogi Guaçu (SP) & 32 & $5.36-1.94$ & 2.80 & 41.03 \\
S. brasiliensis Sprengel, 1825 & Itapagipe (MG) & 32 & $5.04-1.77$ & 2.85 & 38.02 \\
S. campestris Grisebach, 1842 & Caçapava do Sul (RS) & 32 & $6.20-1.95$ & 3.18 & 43.44 \\
S. cissoides Martius ex Grisebach, 1842 & Feira de Santana (BA) & 32 & $5.51-2.00$ & 2.75 & 40.17 \\
S. goyazana A. de Candolle \& C de & Brasilia (DF) & 64 & $4.85-1.61$ & 3.01 & 79.25 \\
Candolle, 1878 & & & & & \\
\hline
\end{tabular}

†In brackets states of Brazil: SP (São Paulo), GO (Goias), MG (Minas Gerais), BA (Bahia), DF (Distrito Federal, Brasília).

the tetraploid $S$. goyazana was carried out by estimating the percentage of the haploid set/2. The diploid-tetraploid comparisons were therefore based on one genome for the expression of the relative chromosome lengths.

Active NORs were detected in metaphase chromosomes of S. rufescens and S. fluminensis, by employing the silver-staining technique according to Stack et al. (1991) with minor modifications as previously reported (Pizzaia et al. 2013). Briefly, roots fixed in 3:1 etanol:acetic acid for $24 \mathrm{~h}$ were used to make squash preparations. The slides were heated for $2 \mathrm{~h}$ at $60^{\circ} \mathrm{C}$, incubated for $8 \mathrm{~min}$ in $2 \mathrm{X} \mathrm{SSC}$ at the same temperature, washed with distilled water (3-5 min) and air-dried. Then, $50 \mu 1$ 100\% silver nitrate solution was added to the preparation, which was then covered with a nylon coverslip and incubated at $60{ }^{\circ} \mathrm{C}$ for $10 \mathrm{~min}$ on a Petri dish with moist filter paper. Coverslips were removed in tap water, and the slides were washed in distilled water, air-dried and mounted in Entellan (Merck, Germany).

Fluorescent in situ hybridization was used to detect $45 \mathrm{~S}$ rDNA sites as previously described (Mondin et al. 2007). Metaphases of S. rufescens and S. fluminensis were investigated. Briefly, the probe used was the $9.1-\mathrm{kb}$ maize $45 \mathrm{~S} \mathrm{rDNA}$ repeating unit labelled with biotin 14-dATP by nick translation (Bionick Labelling System, Invitrogen, USA). Biotin was detected with mouse anti-biotin followed by rabbit anti-mouse and swine anti-rabbit antibodies, both conjugated with TRITC (DAKO, Denmark). The probe $(5 \mathrm{ng} / \mu \mathrm{l})$ was added to the hybridization mixture and denatured by heating at $95^{\circ} \mathrm{C}$ for $10 \mathrm{~min}$. Hybridization was carried out at $37^{\circ} \mathrm{C}$ for $20 \mathrm{~h}$. Post-hybridization steps followed the protocol described by Mondin et al. (2007). The slides were counterstained with $1 \mu \mathrm{g} / \mathrm{ml}$ DAPI in Vectashield (Vector, USA).

All preparations were examined with a Zeiss Axiophot-2-epifluorescence microscope with appropriate filters. The images were acquired by a CCD camera using the IKAROS software to analyze the Feulgen-stained metaphases and the ISIS software for the FISH images (Meta-Systems, Germany). Silver-stained chromosomes were photographed using the Fujicolor Superia 100 film (Fuji Photo Film, Brazil). All images were processed with Adobe Photoshop 6.0. 


\section{Results}

\section{Karyotype anyses}

The experiments to germinate seeds from wild plants were successful for obtaining plants and roots with high index of mitosis. The pretreatments used also provided metaphases suitable for karyotype analysis.

All of the species analyzed had $2 \mathrm{n}=2 \mathrm{x}=32$, except the tetraploid $S$. goyazana with $2 n=4 x=64$. The karyotypes were asymmetric and modal with the chromosomes gradually decreasing in size, as shown in Fig. 1. The lengths of the haploid set and of the largest and smallest chromosomes $(\mu \mathrm{m})$, as well as their ratio, are included in Table 1. The values of relative chromosome length, arm ratio, chromosome type, and Stebbins karyotype classification are given in Table 2. The karyotypes of these species are described for the first time, except for $S$. rufescens (Pizzaia et al. 2013), included here for comparison. The analysis of the karyotypes showed the following characteristics.

\section{S. rufescens Grisebach, 1842}

This species with $2 \mathrm{n}=2 \mathrm{x}=32$ showed a karyotype with 7 pairs of st-type, 6 pairs of sm-type and 2 pairs of $\mathrm{m}$-type chromosomes, and the heteromorphic pair 10 with smand $\mathrm{m}$-type chromosomes with similar sizes, probably sex chromosomes. The size of the chromosomes varied from 1.84 to $5.62 \mu \mathrm{m}$ with a largest/smallest ratio of 3.05 and the Stebbins karyotype classifications was 3B. The total haploid length was $54.24 \mu \mathrm{m}$. Secondary constrictions were detected on the short arms of chromosomes 7, 11 and 14 in some metaphases. These constrictions were visible only in one homologue of each chromosome pair. (Fig. 1A; Tables 1,2). As it was unclear if satellites were visible, the detected structures were considered as secondary constrictions (Pizzaia et al. 2013).

\section{S. fluminensis Steudel, 1841}

Specimens collected from Uruana (GO) and Itirapina (SP) were analyzed. Both specimens had $2 \mathrm{n}=2 \mathrm{x}=32$. The karyotypes were quite similar with slight differences in the arm ratio of chromosomes 7, 8 and 15. The plants from Uruana showed a karyotype with 4 pairs of st-type, 10 pairs of sm-type and 2 pairs with m-type chromosomes. The size of the chromosomes varied from 1.33 to $6.41 \mu \mathrm{m}$ with a largest/ smallest ratio of 4.82 and the Stebbins karyotype classification was 3C. The total haploid length was $43.47 \mu \mathrm{m}$. Secondary constrictions were not detected (Fig. 1B, Tables 1,2). The plants from Itirapina (SP) showed a karyotype with 5 pairs of st-type, 7 pairs of sm-type and 4 pairs of m-type chromosomes. The size of the chromosomes varied from 1.31 to $6.48 \mu \mathrm{m}$ with a largest/ smallest ratio of 4.95 and the Stebbins karyotype classification was 3C. The total haploid length was 43.42 $\mu \mathrm{m}$. A satellite and secondary constriction were detected on the short arm of chromosome 8 and were visible only in one homologue of the chromosome pair (Fig. 1C, Tables 1,2). 


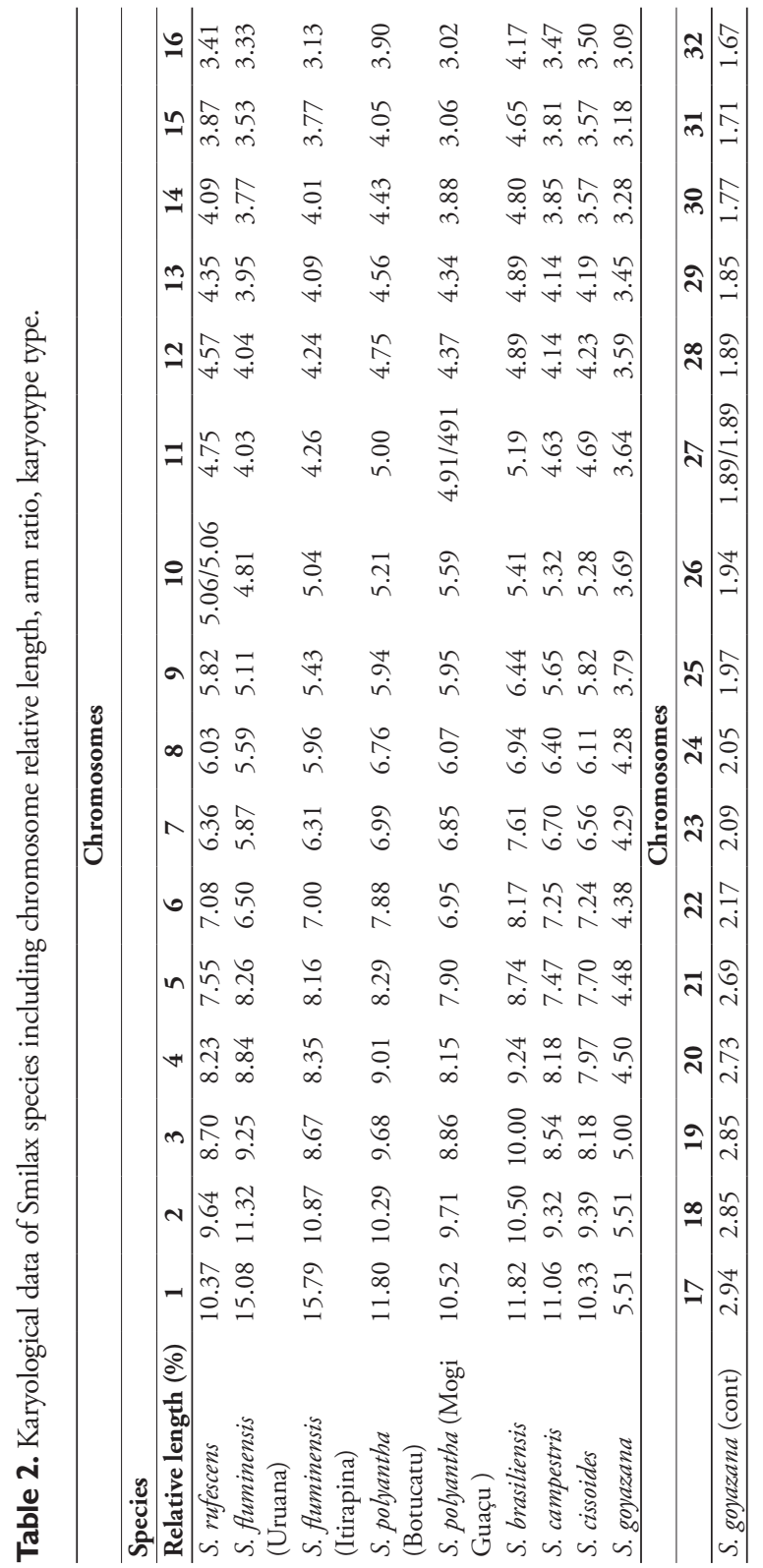




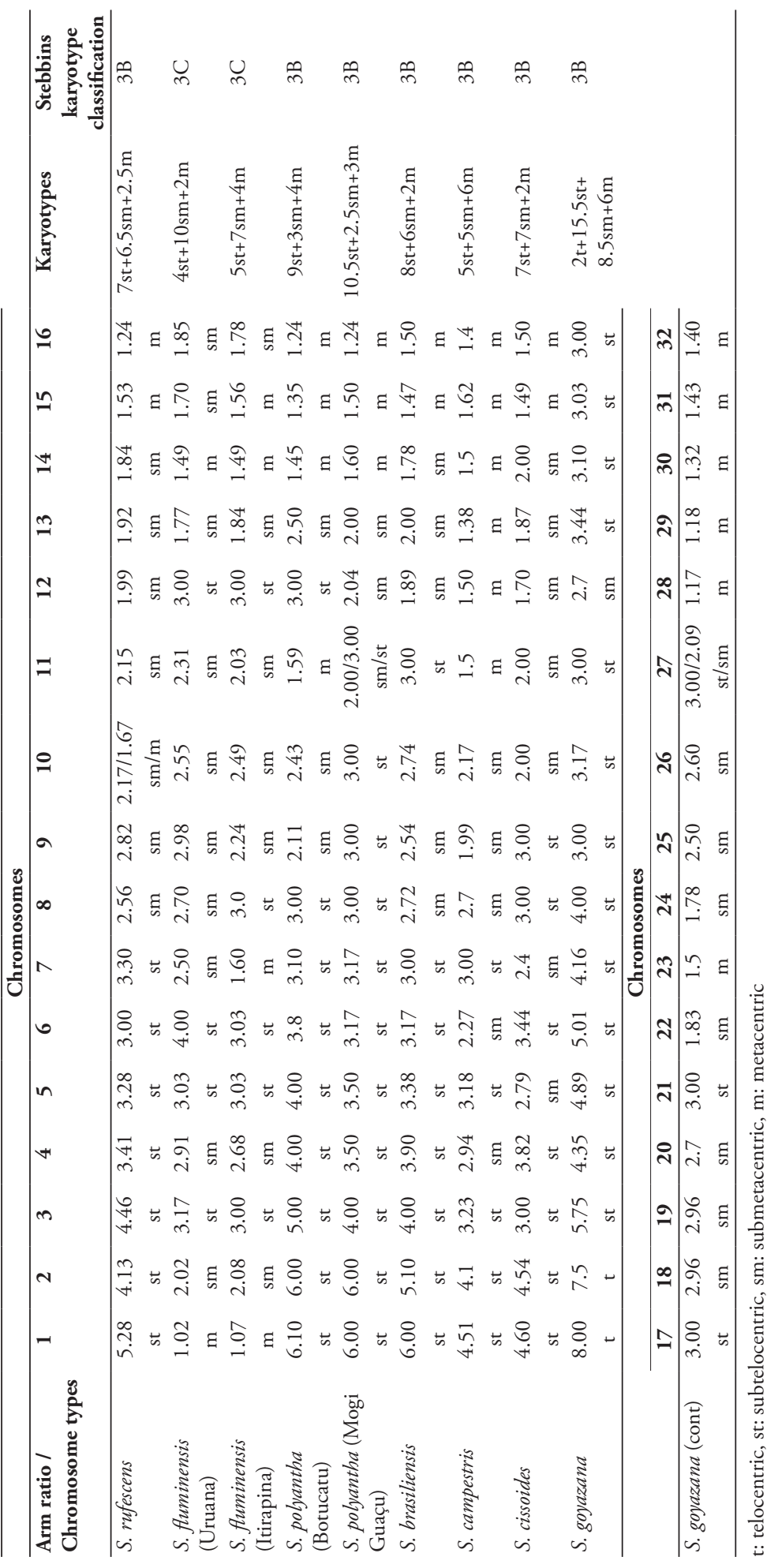




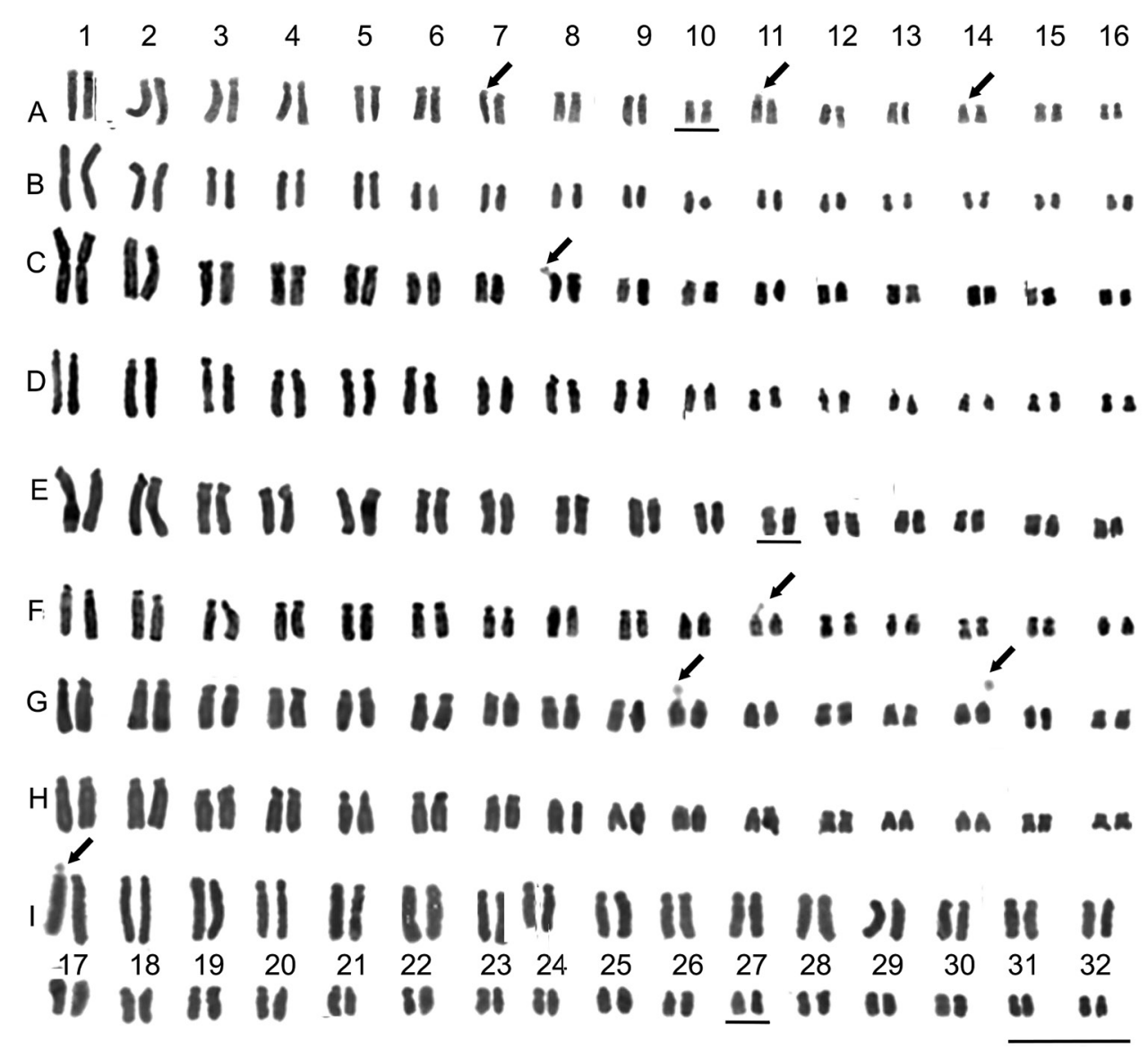

Figure I. Karyotypes of Smilax species: Feulgen-stained metaphase chromosomes. A S. rufescens B S. ftuminensis (Uruana access) C $S$. fluminensis (Itirapina access) D S. polyantha (Botucatu access) E S. polyantha (Mogi Guaçu access) $\mathbf{F}$ S. brasiliensis $\mathbf{G}$ S. campestris $\mathbf{H}$ S. cissoides $\mathbf{I}$ S. goyazana. Arrows indicate secondary constrictions and satellites. Note the heteromorphic pair 10 in S. rufescens, pair 11 in S. polyantha (Mogi Guaçu) and pair 27 in S. goyazana. Scale bar: $10 \mu \mathrm{m}$.

\section{S. polyantha Grisebach, 1842}

Specimens collected from Botucatu (SP) and Mogi Guaçu (SP) were analyzed. Both had $2 n=2 x=32$. The karyotypes were quite similar with slight differences in the arm ratio of chromosomes 9, 10,11 and 12. The plants from Botucatu showed a karyotype with 9 pairs of st-type, 3 pairs of sm-type and 4 pairs of m-type chromosomes. The size of chromosomes varied from 1.92 to $5.85 \mu \mathrm{m}$ with a largest/smallest ratio of 3.05 and the Stebbins karyotype classification was 3B. The total haploid length was 44.09. Secondary constrictions were not detected (Fig. 1D, Tables 1, 2). The plants from Mogi Guaçu (SP) showed a karyotype with 10 pairs of st-type, 2 pairs of sm-type and 3 pairs of $\mathrm{m}$-type chromosomes and the heteromorphic pair 11 with sm-type and 
st-type chromosomes of similar sizes, probably sexual chromosomes. The size of the chromosomes varied from 1.94 to $5.36 \mu \mathrm{m}$ with a largest/smallest ratio of 2.80 and the Stebbins karyotype classification was 3B. The total haploid length was $41.03 \mu \mathrm{m}$. Secondary constrictions were not detected (Fig. 1E, Tables 1,2).

\section{S. brasiliensis Sprengel, 1825}

This species with $2 \mathrm{n}=2 \mathrm{x}=32$ showed a karyotype with 8 pairs of st-type, 6 pairs of sm-type and 2 pairs of $\mathrm{m}$-type chromosomes. The size of chromosomes varied from 1.77 to $5.04 \mu \mathrm{m}$ with a largest/smallest ratio of 2.85 and the Stebbins karyotype classification was 3B. The total haploid length was $38.02 \mu \mathrm{m}$. A satellite and secondary constriction were observed on chromosome 11 and they were visible only in one homologue of the chromosome pair (Fig. 1F, Tables 1, 2).

\section{S. campestris Grisebach, 1842}

This species with $2 \mathrm{n}=2 \mathrm{x}=32$ showed a karyotype with 5 pairs of st-type, 5 pairs of sm-type and 6 pairs of m-type chromosomes. The size of chromosomes varied from 1.95 to $6.20 \mu \mathrm{m}$ with a largest/smallest ratio of 3.18 and the Stebbins karyotype classification was 3B. The total haploid length was $43.44 \mu \mathrm{m}$. Satellites and secondary constrictions were detected on the chromosomes 10 and 14, visible only in one homologue of each pair (Fig. 1G, Tables 1,2).

\section{S. cissoides Martius ex Grisebach, 1842}

This species with $2 \mathrm{n}=2 \mathrm{x}=32$ showed a karyotype with 7 pairs of st-type, 7 pairs of sm-type and 2 pairs of m-type chromosomes. The size of chromosomes varied from 2.00 to 5.51 $\mu \mathrm{m}$ with a largest/smallest ratio of 2.75 and the Stebbins karyotype classification was 3B. The total haploid length was $40.17 \mu \mathrm{m}$. Satellites were not detected (Fig. 1H, Tables 1, 2).

\section{S. goyazana A de Candolle \& C de Candolle, 1878}

This polyploid species with $2 \mathrm{n}=4 \mathrm{x}=64$ showed a karyotype with 2 pairs of t-type, 15 pairs with st-type, 8 pairs with sm-type, 6 pairs with $\mathrm{m}$-type chromosomes and the heteromorphic pair 27 with st-type and sm-type chromosomes with similar sizes. The size of chromosomes varied from $1.61 \mu \mathrm{m}$ to 4.85 with a largest/smallest ratio of 3.01 and the Stebbins karyotype classification was 3B. The total haploid length was $79.25 \mu \mathrm{m}$. A satellite and secondary constriction were detected on the largest and t-type chromosome 1, and it was visible only in one of the homologues (Fig. 1I, Tables 1, 2). 


\section{NOR-regions visualized by silver staining and FISH}

As previously reported (Pizzaia et al. 2013), in situ hybridization detected sites of $45 \mathrm{~S}$ rDNA in six chromosomes of $S$. rufescens. A larger pair of medium-sized chromosomes showed distended secondary constrictions with different lengths between the homologues (Fig. 2A). This pair must correspond to chromosome 7 shown in Fig. 1A. Metaphases with both homologues displaying similar lengths of stretched secondary constrictions were also visualized (not shown). Two pairs of the smallest chromosomes showed minor sites of ribosomal DNA, and they must correspond to pairs 11 and 14, as shown in Fig. 1A. Secondary constrictions were not detected in these small chromosomes in FISH preparations.

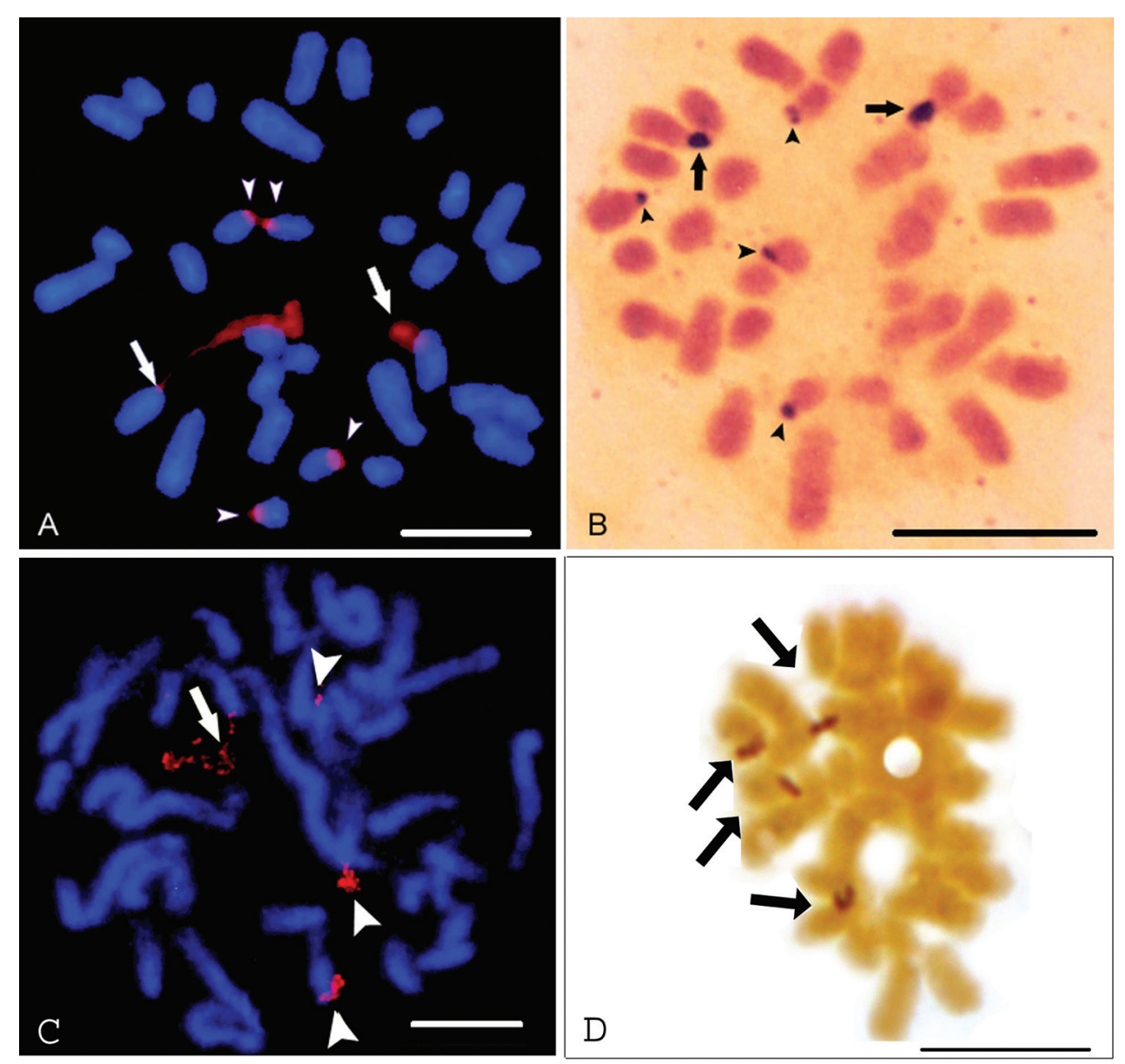

Figure 2. FISH signals of $45 \mathrm{~S} \mathrm{rDNA}$ (red) $(\mathbf{A}, \mathbf{C})$, silver staining $(\mathbf{B}, \mathbf{D})$ in S. rufescens $(\mathbf{A}, \mathbf{B})$ and $S$. fluminensis (C, D). Arrows in $\mathbf{A}$ and $\mathbf{C}$ indicate distended secondary constrictions, and arrowheads show condensed rDNA sites. Arrows in B and $\mathbf{D}$ indicate larger silver signals and arrowheads in B shows small sites. Scale bar: $10 \mu \mathrm{m}$. 
In the silver-stained metaphases of $S$. rufescens, six chromosomes showed positive signals on the termini of the short arms (Fig. 2B), thereby giving evidence that the six sites of rDNA were active. Two chromosomes had larger signals, and minor silverstained sites were observed in four chromosomes, as previously shown (Pizzaia et al. 2013).

In S. fuminensis, only four chromosomes showed $45 \mathrm{~S}$ rDNA sites. In Fig 2C, which illustrates a prometaphase, a highly distended secondary constriction is seen in one medium-sized chromosome that must correspond to the satellited chromosome 8 visualized in Fig 1C. The other two chromosomes show secondary constrictions that are less distended. A small signal is observed in a smaller chromosome. One metaphase with two chromosomes showing highly distended secondary constrictions was also observed (not shown).

In the silver-stained metaphases of $S$. fluminensis, four chromosomes showed positive signals on the termini of short arms (Fig 2D). The signals had the same size.

\section{Discussion}

\section{Karyotype analyses}

All of the diploid species studied here had $2 \mathrm{n}=2 \mathrm{x}=32$, except the polyploid S. goyazana with $2 \mathrm{n}=4 \mathrm{x}=64$. Most diploid species from East Asia and India also have $2 \mathrm{n}=2 \mathrm{x}=32$ (Vijayavalli and Mathew 1989, Fu and Hong 1990, Fu et al. 1993, 1995, Huang et al. 1997, Kong et al. 2007, Sun et al. 2015), while a survey of species from North America (USA) found most of the species with $2 \mathrm{n}=2 \mathrm{x}=26$ and one species with $2 \mathrm{n}=2 \mathrm{x}=30$ (Mangaly 1968). The chromosome number in polyploids is variable $(2 \mathrm{n}=64,96,128$ (Vijayavalli and Mathew 1989, Fu and Hong 1990, Fu et al. 1993, 1995, Kong et al. 2007), all based on $\mathrm{n}=16$. In the present study, the tetraploid S. goyazana has $2 \mathrm{n}=4 \mathrm{x}=64$. In some species, populations with variable numbers of chromosomes were described, such as the $S$. china Linnaeus, 1753 complex, in which diploids $(2 \mathrm{n}=30,32)$ and polyploids $(2 \mathrm{n}=64,96)$ were described (see Sun et al. 2015). The species investigated in our study have $n=16$, thereby giving additional evidence that this must be the basic number in the genus Smilax. The chromosome number of polyploids is also derived from the basic number $\mathrm{x}=16$.

The karyotypes of the species analyzed were asymmetric, and the absolute size of the chromosomes was rather similar, gradually decreasing in size, except in S. fluminensis, in which the metacentric chromosome 1 was larger than in the other species. This finding was clearly emphasized with the evaluation of the ratio between the largest and smallest chromosomes that varied from 2.75 to 3.18 in most species compared with the values of $S$. fuminensis that were larger (4.82-4.95). The relative chromosome lengths were also quite similar with clear differences concerning the relative lengths of chromosome 1 in most species (10.33 to 11.82) compared with S. fluminensis (15.08-15.79). In a general sense, these data were similar to those reported for species from East Asia 
(Fu and Hong 1990, Fu et al. 1993, 1995, Kong et al. 2007). From this finding, we can conclude that chromosomal evolution in Smilax was not accompanied by large modifications in chromosome and haploid set size, as well as large chromosomal rearrangements in the species with $2 \mathrm{n}=32$.

The presence of a large metacentric chromosome 1 in the karyotype of S. fluminensis is a special feature that is unusual in Smilax species. Fu et al. (1995) described the karyotype of $S$. mirtillus A de Candolle \& C de Candlolle, 1878 with a second heteromorphic pair showing $\mathrm{m}$ - and sm-chromosomes as a special karyotype. Additionally, a heteromorphic subtelocentric pair 1 was found in two Smilax species by Fu et al. (1995). A size heteromorphism of the homologues of the satellited pair 7 was detected in male plants of $S$. aspera Linnaeus, 1753 by Vijayavalli and Mathew (1989). These authors assumed an XY (male) and XX (female) type of chromosome sex complex for this species. In our study, in S. rufescens, pair 10 was heteromorphic for their centromere positions, and the chromosomes were not NOR-bearing chromosomes. In S. polyantha (from Mogi-Guaçu) and S. goyazana we also detected heteromorphism related to centromere position in pairs 11 and 27, respectively. As we used young plants, we had no information on their sex, therefore we can speculate only that these heteromorphic pairs are sexual chromosomes. These findings give evidence that differentiated sexual chromosomes must be a characteristic of Smilax karyotypes, however more analyses are needed for deeper conclusions.

In general, the species analyzed had asymmetric karyotypes with chromosomes gradually decreasing in size and showing variability in centromere position. The classification of the karyotypes according to Stebbins (1971) showed that all the karyotypes were classified as 3B, except $S$. fluminensis that was 3C. Interestingly, most karyotypes of species $2 \mathrm{n}=32$ from China, analyzed by Fu et al. (1993, 1995), also belong to class $3 \mathrm{~B}$, with few of them classified as $3 \mathrm{C}$. In the present investigation, in most species, the largest and medium-sized chromosomes were subtelocentric and submetacentric. The smallest chromosomes were submetacentric and metacentric. For instance, $S$. polyantha (from Mogi Guaçu) had the highest number of subtelocentric chromosomes among the largest ones, and in S. campestris, the highest number of submetacentric and metacentric types was detected among the medium-sized and smallest chromosomes. The features observed suggest that during the evolution of these species, slight alterations occurred in the position of the centromeres, probably due to different accumulation of repetitive DNA in chromosome arms, as discussed below. Only S. fluminensis with a large metacentric chromosome 1 suffered a different type of chromosome rearrangement.

The genus Smilax has been assigned to the family Smilacaceae and to the order Liliales sensu APG III thus, it is a sister family of Liliaceae. Peruzzi et al. (2009) considered that the ancestral basic number for Liliaceae is $\mathrm{x}=8$, based on the frequency of counts $2 \mathrm{n}=32$ in Smilax and cytological data suggesting this genus to be paleopolyploid, according to Vijayavalli and Mathew (1989). Peruzzi et al (2009) reported that Smilax species have small mean genome size $(9.16 \mathrm{pg})$ compared with some Liliaceae, such as the genera Streptopus Michaux, 1803 (3.43 pg), and Prosartes D Don, 1830 (5.08 pg), which also have a small mean genome size in contrast with the tribe Lilieae, 
in which genera with large genomes were found: Lilium Linnaeus, 1753 (56.31 pg) Fritillaria Linnaeus, 1753 (44.49 pg), Cardiocrinum Lindley, 1846 (36.18 pg) and Notholirion Boissier, 1889 (27.82 pg).

Peruzzi et al. (2009) suggested that the ancestral Liliaceae species would have a small genome size and that evolution occurred in the direction of increasing size. In general, it is well known that in plants there is a positive correlation between genome size and the amount of repetitive DNA for both in tandem and dispersed repeats. For instance, in maize, the evolution from an ancestral plant occurred with an increase in the content of repetitive DNA. Expressive variation in genome size was observed among maize varieties (Laurie and Bennett 1985). The analysis of the inbred line B73 (reference genome) showed that $85 \%$ of the genome was composed of transposable elements, of which $75 \%$ belonged to LTR retrotransposon families (Schnable et al. 2009). The arm ratios of the knobless chromosomes 2 and 4 of the inbred line KYS compared with their homologues in the tropical JD lines were significantly different, possibly due to differences in their content of repetitive DNA (Mondin et al. 2014). From this scenario, we could infer that the differences in arm ratios observed among Smilax species analyzed in this study are due to different contents of repetitive DNA in their chromosome arms.

Significant differences in karyotype asymmetry are apparent within Liliales, in which two different aspects can be observed, such as variation in chromosome length and variation in centromere position. Variation in chromosome lengths such as the observed in Smilax, was observed in some Liliaceae genera with small genome sizes such as Streptopus and Prosartes, while in some genera, such as Lilium and Fritillaria, the asymmetry is mainly due to variation in the position of centromeres (two large metacentric chromosomes and subtelocentric and telocentric chromosomes with rather similar lengths (see Peruzzi et al. 2009).

Secondary constrictions were not described for the karyotypes of most Smilax species reported in the literature. Vijayavalli and Mathew (1989) detected satellites on the short arm of subtelocentric chromosomes in three species (S. aspera, S. bracteata Presl, 1827 and S. zelanica Linnaeus, 1753) and a secondary constriction on the long arm of chromosome 1 in S. wightii A de Candolle \& C de Candolle, 1753 but did not detect secondary constrictions in the karyotypes of the cytotypes of the polyploid S. ovalifolia Roxburgh, 1832. Fu et al. (1995) reported the presence of secondary constrictions only on the long arm of two subtelocentric pairs (second and third) in S. corbularia Kunth, 1850 in a study involving nine species of Smilax and three species of Heterosmilax. In our study, we detected secondary constrictions on the short arms of subtelocentric chromosomes in S. rufescens, S. fluminensis, S. brasiliensis, S. campestris and the polyploid $S$. goyazana in conventionally stained preparations. All of these constrictions were located on medium-sized and small chromosomes, except for $S$. goyazana which has a large chromosome 1 bearing a secondary constriction and satellite. As discussed below, the $45 \mathrm{~S} \mathrm{rDNA}$ is located on the termini of the NOR-chromosome short arms thus, due to the degree of chromosome condensation, secondary constrictions might not be visualized in conventionally stained chromosomes. 


\section{NOR regions}

In the present study, in situ hybridization of $45 \mathrm{~S}$ rDNA probes showed six sites of ribosomal DNA in S. rufescens and four sites in S. fluminensis. In addition to differing from $S$. rufescens and the other species analyzed by the presence of a large metacentric chromosome 1, S. fuminensis has a different number of ribosomal DNA sites. The number of positive silver-staining signals was correlated with the FISH signals in both species. Terminal secondary constrictions were observed in three chromosome pairs of $S$. rufescens. As it was unclear if satellites were visible, the structures visualized were considered terminal secondary constrictions. In more condensed metaphases, only two chromosomes displayed secondary constrictions (Pizzaia et al. 2013). In the Itirapina access of $S$. fluminensis, only one chromosome exhibited a secondary constriction, and a satellite was observed. In Fig. 1C, the formation of a satellite is more conspicuous. Therefore, in the case of $S$. fluminensis, we find that due to the terminal position of the NOR region and the degree of chromosome condensation, secondary constrictions could not be detected in all chromosomes.

Secondary constrictions have been considered to be the organization pattern of active ribosomal chromatin on metaphase chromosomes. Silver-staining on secondary constriction allows the visualization of ribosomal genes that were transcribed in the previous interphase. It has been shown that silver binds to proteins that are components of the transcription machinery and remain at NOR regions throughout metaphase and anaphase (see revision in Caperta et al. 2002). The organization pattern of the rDNA site visualized by FISH in one metaphase chromosome pair in species such as Secale cereale Linnaeus, 1753 (Caperta et al 2002; 2007) and Zea mays Linnaeus, 1753 (Kato et al. 2004, Mondin et al. 2014) is a distended secondary constriction and a condensed block of proximal ribosomal chromatin, which is transcriptionally inactive. As the NOR region is localized on a subterminal position of the short chromosome arm in these species, a satellite stained by DAPI is visualized. In both S. rufescens and S. fluminensis, a condensed chromatin block was not visualized in the chromosome presenting a distended secondary constriction, and neither a DAPI-stained satellite was detected. This last observation provides evidence that the rDNA sites are localized at chromosome termini. Therefore, we suppose that the satellite observed in the Feulgenstained metaphase of $S$. fluminensis shown in Fig. $1 \mathrm{C}$ would be a structure containing rDNA, as in species of Passiflora Linnaeus, 1753 in which ribosomal DNA was observed on secondary constrictions and satellites (Cuco et al. 2005).

Details on the structure and function of the NOR chromosomes, as well as the quantification of observed events were not the scope of this study, but the detection of some features allows some discussion. The presence of positive-silver staining signals corresponding with the number of rDNA sites revealed by FISH showed that all these loci were active in both species analyzed. However, in some Feulgen-stained metaphases of $S$. rufescens only two chromosomes bearing secondary constriction were observed (Pizzaia et al. 2013), whereas in the metaphase of S. fluminensis seen in Fig. 
1B, secondary constrictions were not detected, and in Fig. 1C, only one was observed. As mentioned above, these findings are a consequence of the terminal position of the rDNA loci and the degree of chromosome condensation not allowing the visualization of the secondary constrictions. Additionally, in the FISH preparation of $S$. rufescens shown in Fig 2A, one largest NOR chromosome has a secondary constriction that is highly distended in comparison with its homologous. This chromosome would be more active than its homologue. This heteromorphism of the secondary constriction was observed in FISH preparations of $S$. cereale, giving evidence of differential expression of homologous rDNA loci (Caperta et al. 2002; 2007). This behavior was also supported by the observation of differences in the size of the silver-staining signals. In an experiment carried out to evaluate this event, metaphases showing heteromorphic secondary constriction were more frequent than the homomorphic ones, and the rDNA loci on homologous chromosomes had equivalent numbers of ribosomal cistrons (Caperta et al. 2002).

In the present study, heteromorphic secondary constrictions were detected in FISH preparations of S. rufescens and S. fuminensis, but metaphases with both homologues of the largest NOR chromosome pair displaying distended secondary constrictions were also observed (not shown).Therefore, we conclude that in these species, differential expression of rDNA loci occurs only in some cells. The observation of homologous NOR chromosomes showing differences in the presence of secondary constrictions in Feulgen-stained metaphases of S. rufescens, S. fluminensis and also in S. campestris, S. cissoides and $S$. goyazana suggests that differential expression of rDNA loci is frequent in the genus Smilax.

Interestingly, the treatment of roots of $S$. cereale with the methyltransferase inhibitor 5-azacytidine (5-AC) resulted in an increase of rRNA gene transcription and then in a reduction in the number of cells showing a significant difference in the size of silver-stained domains in the two NORs (Caperta et al. 2007). The authors concluded that ribosomal gene silencing was controlled by DNA methylation and that rRNA gene transcription, silver-staining and NOR chromatin decondensation were interrelated in S. cereale. Fig 2B shows two apparently non-homologous chromosomes of S. rufescens with larger silver-stained domains, suggesting the occurrence of differential rRNA expression. Fig 2D illustrates NOR chromosomes of $S$. fluminensis with silverstained NORs of similar sizes. These observations provide evidence that differential rRNA gene expression, as well as equal expression occur in these species.

The differential expression between homologous NOR chromatin is a different phenomenon in relation to nucleolar dominance. Nucleolar dominance has been characterized as an epigenetic phenomenon that occurs in plant allopolyploids and hybrids, in which only one ancestral set of ribosomal genes retains the ability to organize the nucleolus, while the rDNA loci derived from the other progenitor are silenced. For instance, in Atropa belladonna Linnaeus, 1753 derived from a tetraploid and a diploid ancestor species, only four out of six rDNA sites are transcriptionally active, as revealed by silver-staining (Volkov et al. 2017). In Quercus robur Linnaeus, 1753, two 
rDNA loci were observed, NOR-1 and NOR-2 (Bockor et al. 2014). Only NOR-1 showed decondensed chromatin in FISH preparations and positive silver signals. In interphases, NOR-2 was condensed and located away from the nucleolus, while the major locus (NOR-1) was associated with the nucleolus and exhibited different degrees of condensation. Treatment with 5-azacytidine increased the total level of RNA transcripts and decreased the degree of DNA methylation at NOR-2 site however, the chromatin condensation of this locus was not affected, suggesting that NOR-2 has lost the function of rRNA synthesis and nucleolus organization.

\section{Conclusions}

The karyotypes of seven Brazilian Smilax species investigated were asymmetric and modal with $2 \mathrm{n}=2 \mathrm{x}=32$ chromosomes gradually decreasing in size. In S. goyazana, a polyploid species, $2 \mathrm{n}=4 \mathrm{x}=64$. In all the species, the large and medium-sized chromosomes were subtelocentric and submetacentric and the small chromosomes were submetacentric or metacentric. Their karyotypes were quite similar, with slight differences in the arm ratio of some chromosomes and belong to class $2 \mathrm{~B}$ according with Stebbins classification (1971). S. fluminensis differed from the other species by having a large metacentric chromosome 1 and belonging to class 3C. These findings suggest that evolution occurred without drastic changes in karyotype structure in the species analyzed, except $S$. fluminenesis. Terminal secondary constrictions were visualized on the short arm of some chromosomes, but they were detected only in one homologue of each pair. Due to the terminal location and the degree of condensation of the chromosomes, secondary constrictions were not visualized in some species. In S. rufescens and S. fluminensis all the rDNA loci were active as demonstrated by silver-staining signals colocalized with the FISH signals. We concluded that differential expression of rDNA loci occurs in these species based on the observation of a distended secondary constriction in the largest NOR chromosome visualized in FISH preparations of some cells in both species. Distended secondary constrictions were not observed in the smallest chromosomes, probably due to their small size and the degree of metaphase condensation. In this connection, it is interesting to note that the absence of secondary constriction on an active locus was observed in Crotalaria juncea Linnaeus, 1753, in which two silver-stained rDNA loci were observed, that is, one major locus showing secondary constriction and one minor locus in which a secondary constriction was not detected (Mondin et al. 2007). The largest silver signals were observed in two chromosomes in S. rufescens, while signals with the same size were observed in S. fluminensis, demonstrating, in this species, that differential expression of rRNA genes does not occur in some cells. Additionally, the observation of homologous NOR chromosomes with differences in the presence of secondary constrictions in Feulgen-stained metaphases of $S$. rufescens, S. fluminensis, and in S. campestris, S. cissoides and S. goyazana suggests that Smilax is an interesting genus for further studies on the activity of the NOR sites. 


\section{Acknowledgments}

We acknowledge the support of the Fundação de Apoio à Pesquisa do Estado de Sáo Paulo (FAPESP, Project BIOTA, \#05/58964-9), of the Conselho Nacional de Desenvolvimento Científico e Tecnológico (CNPq), of Dr. Beatriz Appezzato-da-Glória (University of São Paulo) and Dr. Eliana R. Forni-Martins (The University of Campinas) for cooperation in this research, and Mrs. S. C. M. Molina for technical assistance.

\section{References}

Andreata RHP (1995) Revisão das espécies brasileiras do gênero Smilax Linnaeus (Smilacaceae). PhD Thesis, Instituto de Biociências, Universidade de São Paulo, São Paulo, 397 pp.

Andreata RHP (2009) A new species of Smilax and key to all species of Minas Gerais, Brasil. Systematic Botany 34: 28-31. https://doi.org/10.1600/036364409787602302

Bertão MR, Aguiar-Perecin MLR (2002) Maize somatic chromosome preparation: pretreatments and genotypes for obtention of high index of metaphase accumulation. Caryologia 55: 115-119. https://doi.org/10.1080/00087114.2002.10589266

Bockor VV, Barisic D, Horvat T, Maglica Z, Vojta A, Zoldos V (2014) Inhibition of DNA methylation alters chromatin organization, nuclear positioning and activity of $45 \mathrm{~S} \mathrm{rDNA}$ loci in cycling cells of Q. robur. PLoS ONE 9(8): e103954. https://doi.org/10.1371/journal.pone.0193954

Caperta AD, Neves N, Morais-Cecilio L, Malhó R, Viegas W (2002) Genome restructuring in rye affects the expression, organization and disposition of homologous rDNA loci. Journal of Cell Science 115: 2839-2846.

Caperta AD, Neves N, Viegas W, Pikaard CS, Preuss S (2007) Relationships between transcription, silver staining, and chromatin organization of nucleolar organizers in Secale cereale. Protoplasma 232: 55-59. https://doi.org/10.1007/s00709-007-0277-4

Cox SD, Jayasinghe KC, Markham JL (2005) Antioxidant activity in Australian native sarsaparilla (Smilax glyciphylla). Journal of Ethnopharmacology 101: 162-168. https://doi. org/10.1016/j.jep.2005.04.005

Cuco SM, Vieira MLC, Mondin M, Aguiar-Perecin MLR (2005) Comparative karyotype analysis of three Passiflora L. species and cytogenetic characterization of somatic hybrids. Caryologia 58: 220-228. https://doi.org/10.1080/00087114.2005.10589454

De Souza GC, Haas AP, von Poser GL, Schapoval EE et al. (2004) Ethnopharmacological studies of antimicrobial remedies in the south of Brazil. Journal of Ethnopharmacology 90: 135-143. https://doi.org/10.1016/j.jep.2003.09.039

Fu C-X, Hong D-Y (1990) A chromosomal study on 7 species of Smilax L. Acta Phytotaxonomica Sinica 28: 211-222.

Fu C-X, Shen C-D, Zhong G-Q, Hong D-Y (1993) Variation and evolution of the karyotype on Smilax II. Karyotypic analysis of seven species from southern China. Cathaya 5: 151-166. 
Fu C-X, Shen C-D, Huang, A-J, Hong D-Y (1995) Variation and evolution of the karyotype in Smilax and Heterosmilax (Smilacaceae) III. Analyses of karyotypes and evolution from twelve taxa in southern China. Cathaya 7: 105-124.

Huang A, Shen C, Fu C (1997) The chromosome numbers of 13 species in Smilax L. Journal of Wuhan Botanical Research. 15: 279-280.

Kato A, Lamb JC, Birchler JA (2004) Chromosome painting using repetitive DNA sequences as probes for somatic chromosome identification in maize. Proceedings of the National Academy of Sciences U.S.A. 101: 13554-13559. https://doi.org/10.1073/pnas.0403659101

Kong H-H, Wang A-L, Lee J, Fu C-X (2007) Studies of systematic evolution and karyotypic variation in Smilax and Heterosmilax (Smilacaceae). Acta Phytotaxonomica Sinica 45: 257 273. https://doi.org/10.1360/aps050125

Koyama T (1960) Materials toward a monograph of the genus Smilax. Quarterly Journal of the Taiwan Museum 13: 1-61.

Laurie DA, Bennett MD (1985) Nuclear DNA content in the genera Zea and Sorghum: intergeneric, interspecific and intraspecific variation. Heredity 55: 307-313. https://doi. org/10.1038/hdy.1985.112

Levan A, Fredga A, Sanderberg AA (1964) Nomenclature for centromeric position on chromosomes. Hereditas 52: 201-220. https://doi.org/10.1111/j.1601-5223.1964.tb01953.x

Mangaly JK (1968) A cytotaxonomic study of the herbaceous species of Smilax section Coprosmanthus. Rhodora 70: 55-82.

Martins AR, Appezzato-da-Glória (2006) Morfoanatomia dos órgãos vegetativos de Smilax polyantha Griseb. (Smilacaceae). Revista Brasileira de Botânica 29: 555-567. https://doi. org/10.1590/S0100-84042006000400005

Martins, AR, Pütz N, Soares AS, Bombo Appezzato-da-Glória B (2010) New approaches to underground systems in Brazilian Smilax species (Smilacaceae). The Journal of the Torrey Botanical Society 137: 220-235. https://doi.org/10.3159/10-RA-024R.1

Martins AR, Soares AS, Bombo, AB, Fidelis A, Novembre ADLC, Appezzato-da-Glória B (2012) Germination and seedling morphology of four South American Smilax (Smilacaceae). Revista de Biología Tropical 60: 495-504. https://doi.org/10.15517/rbt.v60i1.2784

Mehra PN, Sachdeva SK (1976) Cytological observations on some W. Himalayan monocots II. Smilacaceae, Liliaceae and Trilliaceae. Cytologia 41: 5-22. https://doi.org/10.1508/cytologia.41.5

Mondin M, Santos-Serejo JA, Aguiar-Perecin MLR (2007) Karyotype characterization of Crotalaria juncea (L.) by chromosome banding and physical mapping of 18S-5.8S-26S and 5S rRNA gene sites. Genetics and Molecular Biology 30: 65-72. https://doi.org/10.1590/ S1415-47572007000100013

Mondin M, Santos-Serejo JA, Bertão MR, Laborda P, Pizzaia D, Aguiar-Perecin MLR (2014) Karyotype variability in tropical maize sister inbred lines and hybrids compared with KYS standard line. Frontiers in Plant Science 5: 544. https://doi.org/10.3389/fpls.2014.00544

Peruzzi L, Leitch IJ, Caparelli KF (2009) Chromosome diversity and evolution in Liliaceae. Annals of Botany 103: 459-475. https://doi.org/10.1093/aob/mcn230

Pizzaia D, Oliveira VM, Martins AR, Appezzato-da-Gloria B, Forni-Martins E, Aguiar-Perecin MLR (2013) Karyotype characterization reveals active 45S rDNA sites located on chro- 
mosome termini in Smilax rufescens (Smilacaceae). Genetics and Molecular Research 12: 1303-1310. https://doi.org/10.4238/2013.April.25.1

Schnable PS, Ware D, Fulton RS, Stein JC et al. (2009) The B73 maize genome: complexity, diversity, and dynamics. Science 326: 1112-1115. https://doi.org/10.1126/science.1178534

Stack S, Herickhoff L, Sherman J, Anderson L (1991) Staining plant cells with silver. I. The salt-nylon technique. Biotechnic \& Histochemistry 1: 69-78. https://doi. org/10.3109/10520299109110553

Speese BM (1939) Mitosis in leaves of Smilax. American Journal of Botany 26: 852-855. https://doi.org/10.1002/j.1537-2197.1939.tb09367.x

Stebbins GL (1971) Chromosomal evolution in higher plants. Edward Arnold Ltd, London, 216 pp.

Sun Z-S, Wang Y-H, Zhao Y-P, Fu C-X (2015) Molecular, chromosomal and morphological characters reveal a new diploid species in the Smilax china complex (Smilacaceae). Phytotaxa 212: 199-212. https://doi.org/10.11646/phytotaxa.212.3.2

The Angiosperm Phylogeny Group (2009) An update of the Angiosperm Phylogeny Group classification for the orders and families of flowering plants: APG III. Botanical Journal of the Linnean Society 161: 105-121. https://doi.org/10.1111/j.1095-8339.2009.00996.x

Vijayavalli B, Mathew PM (1989) Karyomorphology of five South Indian species of Smilax Linn. Cytologia 54: 65-72. https://doi.org/10.1508/cytologia.54.65

Volkov RA, Panchuk II, Borisjuk N, Hosiawa-Baranska M, Maluszynska J, Hemleben V (2017) Evolutional dynamics of $45 \mathrm{~S}$ and $5 \mathrm{~S}$ ribosomal DNA in ancient allohexaploid Atropa belladonna. BMC Plant Biology 17: 21-35. https://doi.org/10.1186/s12870-017-0978-6 